\title{
Research on Restriction Policy of Wuhan Based on Public Policy
}

\author{
Junjie Liu \\ Wuhan University of Science \& Technology \\ Wuhan, China
}

\author{
Lu Qiu* \\ Wuhan University of Science \& Technology \\ Wuhan, China \\ *Corresponding author
}

\begin{abstract}
As the pillar industry and leading industry of the country, the real estate industry plays an important role in the continuous rapid growth of the national economy. In recent years, China's real estate industry is booming with the development of social economy and the advancement of urbanization. But the problems such as overheating of the real estate investment, high housing price income ratio, fast rising of housing price gradually exposed because the real estate market is relatively immature. It is divorced from the normal level of our residents and economic development and a series of problems were spawned. The housing economy has been bubbly. The central government made a series of administrative, land, finance, taxation and other aspects of policies to control housing prices, aimed at "stabilize housing prices" and "promote the reasonable return of house prices". The local government of Wuhan had adopted the real estate policy in accordance with the local conditions to implement the central government's public policy on real estate regulation. What is the result of policy regulation? Did it meet expectations? In the current reality, what should be the next direction and step? To answer these questions, based on public policy perspective and, the research on purchase restriction policy of Wuhan was conducted., Combined with the development background of Wuhan and analysis the effect of the restrictions, limit optimization reform, deepen the understanding of the relationship between government and market, so as to promote the Wuhan "stable prices" goal to provide theoretical basis and the reference suggestion.
\end{abstract}

Keywords—purchase order; public policy; Wuhan city

\section{INTRODUCTION}

\section{A. Research Background}

Real estate is a special commodity with dual attributes of consumption and investment. As consumer goods, housing and food are the basic needs of daily life, affecting the living state of thousands of families, which is a great event for the national economy and the people's livelihood. As an investment, the property market and the financial market have a very close relationship with its value. At the same time, the real estate industry has a strong correlation with a large number of upstream and downstream products, involving more than 60 related industries. The above reasons determine the development of real estate directly related to the healthy development of national economy and social harmony and stability. Since 1994, our government has been conducting macro-control of the real estate market. Since 2005, the government has introduced various regulatory policies in a more intensive manner, but the price of housing has increased.

The prosperity and development of the real estate market, the rapid rise in commodity prices, although become the new economic growth point, boost the economic growth, but the commercial housing price rises has severely exceeded the household income growth, China's real estate bubble problems began to emerge. The real estate market in China started late, development is fast, the market itself has many problems, these problems caused the extensive concern of our government and the central government to strengthen macro-control launched a series of management policy and economic measures, intention of stable and high housing sales price.

On April 17, 2010, issued by the general office of the state council "about resolutely curb the property price hikes in some cities notice" (hereinafter referred to as the new "the ten countries"), the first official put forward the train of thought for purchasing, and follow-up in 2011 issued a "new eight", the latest "the five", etc. Wuhan municipal government also according to the central spirit of macroeconomic regulation and control in March 2011, the policy of restrictions on, but no matter what kind of policy, the government formulated measures, to restrict prices play a fundamental role, commodity house prices do not drop, repeatedly even grow, the effect of carrying out the policy clearly didn't achieve their goals.

So in this background, this article is based on public policy perspective, through the restrictions of Wuhan, Wuhan development background on analysis the effect of the restrictions, restrictions on optimizing reform, deepen the understanding of the relationship between government and market, to promote the Wuhan "stable prices" goal to provide theoretical basis and the reference suggestion.

\section{B. Research Significance}

In theory, it can help to make up for the lack of research on real estate regulation policies. Academic research on the real estate purchase restriction policy and the policy of China's real estate purchase restriction. The research on this problem is limited to the legality, validity and the expected execution period of the restriction policy, which lacks the actual case analysis. This paper analyzes the actual situation of implementing the purchase restriction policy in Wuhan in 
recent years and makes up for the deficiency of relevant researches.

In the practical sense, it can help Wuhan municipal government to treat both the symptoms and the root in macrocontrol, improve policy efficiency, and provide a reference basis for improving the macro-control of real estate in Wuhan. This paper provides policy Suggestions for constructing the real estate control mode in Wuhan.

\section{BASIC THEORY OF REAL ESTATE REGULATION}

\section{A. The Necessity of the Purchase Order}

In the market economy condition whether can carry out "limit purchase order" this kind of administrative regulation method, the answer is affirmation.

First, the market is not omnipotent, with the limitations of spontaneity, blindness and stagnation. Any market, including the real estate market, can sometimes fail, and that needs to be addressed through planning control. "Restriction order" is the means of administrative control, which can also be called the planning mechanism in a certain sense. China's real estate market has seen a surge in land prices, soaring housing prices and rampant speculation. The higher the price of overpriced land, the higher the price of the macro-control, is a sign of market failure and is very serious. In this case, as a responsible government, there is every reason and should use the planning mechanism to regulate and eliminate such irrational phenomena.

Secondly, China's land resources are scarce, and land is a limited non-renewable resource. With the development of economy and the increase of population, the demand for land will increase. Because of the public ownership of land in China, the land, including real estate, must serve the people's livelihood, but not the minority developers and speculators.

Thirdly, the land has the characteristics of preservation and appreciation. Even if investors do not invest more, the land will appreciate because of changes in infrastructure and environment, such as transport and commerce. The implementation of the "purchase order", namely, the use of the planning mechanism to limit speculation by developers and speculators, curb the price of land and the surge of housing prices, so that the land can truly serve the masses.

\section{B. Target of Real Estate Regulation}

On the one hand, it is the regulation of real estate price, which is to guarantee the financial security of the country in the market. On the other hand, providing affordable housing is to protect people's lives outside the market.

As an important indicator of real estate, house prices should run smoothly within a reasonable range to ensure the healthy development of the real estate market. Once a property price rises or falls rapidly, it will have a negative impact on real estate and a social economy. It is the main economic demand of the target of housing price control to make the price of housing land stable and steady development. The second is social appeal. To achieve "home ownership" living dream, meet the people's reasonable housing demand, guarantee the development of national economy, and improve people's living standards, building a harmonious socialist society.

\section{IMPLEMENTATION OF RESTRICTION POLICY AND MARKET FEEDBACK IN WUHAN}

\section{A. Implementation phase of wuhan purchase restriction policy}

Wuhan implements the purchase restriction policy, divides into two phases. The first phase is from April 2011 to September 2014.

In April 2011, the ministry of housing and construction released the first list of restricted cities, and Wuhan, one of forty-one restricted cities, began implementing the restriction. Family has a set of housing the city residents (including both sides of husband and wife and minor children, the same below), can provide local tax certificate or one year social insurance payments of the city residents family, one for purchasing homes.

By September 23, 2014, "six" was launched. The provincial construction department suggested that the city should adjust the restrictions on housing purchase restrictions in accordance with market changes, and announce the end of the purchase limit.

The second phase, which restarted in October 2016, has not been lifted.

On December 22, 2016, the restriction of purchase restriction and restriction of purchase scope expanded further. Scope of Wuhan city housing purchase new Dongxihu, Jiangxia district, part of the Huangpi district, the new area is restricted and central city and the three functional areas, namely the city household register to suspend in the above areas buying third homes, not need to pay the full two years in a row that buy a house of the city's census register or the individual income tax of social security.

\section{B. Market Feedback of the Restriction Policy}

1) Market feedback from April 2011 to September 2014: In the first quarter of 2011, in the first quarter of 2013, in the first quarter of 2013, in the nine quarters of the first quarter of 2013, wuhan's house prices fell overall, according to the wuhan housing security and housing authority's wufang index.

In the third year of the restriction, the sale of real estate has been restrained, and the development of new buildings has been reduced, resulting in the local government's unpurchased land and the serious impact of local government's finances. The upstream building materials business cannot produce normally, the downstream construction unit has no project construction; the bank cannot lend to the real estate sector, and the upstream and downstream enterprises have no good effect and have no money to deposit, which has impacted the normal operation of the bank.

However, after the end of the first phase of restrictive purchase policies, easy credit policies have kept the market in Wuhan growing. The psychology that buys rise and not buy fall, let the home buyer of the market more and more, the 
outside company is crowded into, housing price in Wuhan passes a short period of rest, again starts the quantity price to fly again.

Since March 2016, after several rounds of climbing, the housing price in the second ring of Wuhan has been more than Eighteen thousand yuan, with an increase of more than $50 \%$. Downtown high-end real estate prices have also achieved a few level jump, in Hankou street flowers floor "and Huang Shiji jiang shang", for example, in April and May of this year, the price is in Twenty thousand yuan/square meters floating, in August the price up to up to Thirty-four thousand yuan/square meters, up about $70 \%$.

Not only that, the land auction market soaring premium rate, even the floor price is higher than the regional house prices directly, also constantly hit everyone's price expectations, is described as "the flour had become more expensive than the bread".

At the same time, the regulation of the first stage of the purchase restriction failed.

2) The second stage of market feedback since September 2016: First, the decline in the central city is clear, and the daily turnover has fallen to single digits.

According to the data of Wuhan real estate information network, A thousand and sixty-seven sets of houses were sold in wuhan city on Oct. first, with Two hundred and twenty-three units in the riverbank district.

Since October forth, the pattern has changed since the implementation of the restriction: on April four, there were Two hundred and seventy-one sets of sales rooms in Wuhan, among which the Caidian district was the first in seventy sets.

Compared with the new downtown area of the leading role, there is little turnover in the central urban area within the limits of purchase. After four days, the daily turnover of the river bank, Jianghan, Hanyang, Wuchang and other areas plummeted from nearly one thousand sets to single digits, with the turnover of three days in the area of Jianghan district, and Wuchang district for four consecutive days.

Wuhan city housing authority, thought to be the New Deal to the problem of central city land price, house prices rising too fast for the regulation and effectively curb speculative housing demand, nonlocal census register buyers dramatically reduced.

Secondly, the improvement of the ethnic group and the investment community is a strong view.

The New Deal has an obvious impact on the improvement of buyers and buyers, but it is not enough to buy the first housing. According to the survey, a five percent increase in the down payment, while increasing the purchase cost of the first group buying the first home, does not change the purchase plan.

\section{EVALUATION AND REFLECTION OF WUHAN PURCHASING RESTRICTION POLICY}

\section{A. Achieve Periodic Positive Effects}

According to the market feedback of chapter three, the restriction of purchase restriction in the implementation process of the control volume feedback is obvious. Namely, the implementation of the purchase restriction policy and the implementation of the short term are very necessary.

The policy is to stabilize house prices by curbing investment and speculative buying and lowering expectations for real estate prices. And restrictions because of their special pertinence and mandatory, did a period during a crackdown on speculative housing demand, makes growth drop in property prices, in a relatively short period of time have played an important role in "TuiShaoZhen", stabilize the property market. On the one hand, it has stabilized the housing price, restrained the accumulation of the real estate bubble, prevented the financial market from getting out of control, and won the time for the government to set up a long-term real estate control policy. On the other hand also shows that the government paid close attention to the livelihood of the people, promote the social stability and harmony, to curb property prices rose rapidly, safeguard national especially in the housing needs of low-income people.

\section{B. The Regulation Policies and Effects Lack Long-term Validity and Validity}

The real estate purchase restriction policy is the administrative intervention in the real estate market, but the unconventional means used in the special period should not be implemented in the long run. This is because, pertinence and mandatory restrictions through its characteristic, exclude the investment home buyers in the market demand, which broke the prices in the short term support itself, that house prices return to equilibrium level for a long time.

But as an administrative intervention, long-term resistance to investment demand will not only affect demand, but also reduce supply, which will not be conducive to the healthy development of the real estate market. And government intervention too long, real estate from market acceptance regulation for a long time, will affect people's right of the house prices, formation and government policy makers, "on" the non-cooperative game, or fuel prices rise, or lead to the real estate market chaos.

In terms of the validity of the market feedback, the market has rebounded rapidly. Prices have skyrocketed and land Kings have been frequent. The aim of the "purchase order" policy is to reduce the volume by suppressing demand and by reducing the price of housing through the market law of oversupply, so as to buy time for the later demand of market supply.

But the policy of the planning for purchasing is too strong, some strict, suppressed demand is actually cannot effectively resolve, can only be temporary backlog, once the restrictions has been released, will rebound, the market for "phenomenon" will return again, the housing prices again. In addition, the supply glut is formed under the policy intervention, even if the market supply of a large number of launches, late in the case of abundant cash flow, the developer will not let this "golden" opportunity to support prices. Therefore, during the "purchase order" period, the government formulated and implemented the continuous control demand and long-term supporting policies. 


\section{Reflection on the Policy of Purchasing Restriction in Wuhan}

At present, the main driving force of Wuhan's purchase restriction policy is the national policy requirements, but in the case of Wuhan development, whether the long-term implementation of the purchase restriction policy is more beneficial than the advantages or disadvantages?

First, the current Wuhan prices are reasonable range, not inflated. In terms of supply and demand, there is not enough room available in the market for the present. Wuhan will have the support of purchasing demand in the coming years. In terms of macro benefits, Wuhan, Shanghai and Chongqing will be the largest cities, and the landing of the Wuhan free trade area will also usher in a further development of the economy, with higher expectations for future house prices. Net population bonus, population increment will is the ultimate goal, in the development of Wuhan urban development planning, corporate landing is to attract people into the building foundation, with the massive growth of population, the housing purchase demand will also be greatly increased. Real estate bubble is convenient, Wuhan prices at present stage and firsttier cities gap is larger, the bubble is not real, more real house prices is suppressed, and the individual consumption of future three to five years ahead of regional planning.

Therefore, the price of Wuhan is still in reasonable range, and it is not reasonable to restrain the housing price in order to prevent the healthy development of Wuhan real estate.

Second, in the buyer's subject, the only beneficiary of the restriction policy is the first set of buyers who have some economic strength. And most of the low - and middle-income people who do not have the ability to buy a house are not included. In the absence of other relevant policies, the longterm implementation of the restriction policy clearly does not meet the objectives of China's real estate regulation policy in chapter two. Moreover, the long-term implementation of the restrictions will affect the economic development of Wuhan, which will further reduce the economic strength of those in low - and middle-income countries and make it more difficult to buy a house.

Third, the purchase restriction policy will be a mistake for improving the property buyers.

According to the data released by the real estate market information network, the number of household transactions in Wuhan area, which was originally required to be the dominant ninety square meters, is gradually decreasing, with a few months accounting for less than thirty percent. However, the improvement of ninety to one hundred and forty square meters has become the main force of homebuyers, accounting for nearly sixty percent of the total, and the trend is gradually expanding.

To sum up, Wuhan's long-term restriction of purchase restriction has done more harm than good.

\section{CONCLUSION}

The purchase order is like a powerful "annealing needle" for house prices, but cannot be taken for long periods of time, and cannot be used as a long-term mechanism for controlling real estate. We need to give enough patience and confidence to the housing market to return to reason. Here are some Suggestions for the regulation of Wuhan real estate.

\section{A. Apply administrative policies to adjust the housing} structure and improve the housing guarantee system

The regulation of real estate in Wuhan ensures the healthy and good development of real estate and needs to use administrative means to adjust the housing structure and improve the housing guarantee system.

In terms of housing structure, the government should make full use of the actual situation of market supply and demand and adjust the housing structure by means of administrative means to increase the total supply of housing. Rational use of administrative resources can optimize the allocation of resources and encourage developers to build small and medium-sized houses to meet the needs of buyers.

We will improve the housing security system and build a multi-level housing guarantee system in the area of housing.

First, the price of affordable housing should be established, which is in line with the capacity of low-income people in cities. The price of affordable housing can be allocated free of charge through construction land; Establish non-profit organizations to prepare, build and manage affordable housing; Subsidies for special poor families; Under the premise of ensuring the quality of the house, control the per capita area of the lower level to reduce the construction cost of the guarantee room and let more people enjoy the policy.

Secondly, we will formulate the standard of access and exit for the protection of science. There are about 80 percent of China's low - and middle-income people, and the income gap between people of low - and middle-income people is also very large. Therefore, we should elaborate the grading admittance standard and provide different degrees of guarantee for the science of different family conditions to achieve the goal of "home ownership".

\section{B. Use land policies to increase housing improvement and supervision}

Wuhan market supply at the present stage just need and improve sexual demand, by restrictions of housing demand is just take temporary solution not effect a permanent cure, once the cancellation of restrictions, this part of the demand will be rekindled. Therefore, during the implementation of the restriction, we must unswervingly increase the supply of housing, and maximize the effective formation of supply and demand balance.

At the same time, the government of Wuhan should attach great importance to the policy and regulation of state-owned land use right and actively optimize and improve the land market supervision. Is a reasonable optimization adjustment of the current condition of the land finance of Wuhan, scientific land supply plan, determine the quantity and structure of land supply, land planning purposes and construction key points, and ask the enterprise developers plan strictly abide by the regulations for real estate development and use, through the 
government regulation to promote marketization of land configuration, promote the healthy and benign development of land market. The second is to strengthen the impartiality and transparency of the process of land transfer, and limit the actions of the government of Wuhan to land the land and sell the land at a high price. Third, we will conduct regular inspections of land use, crack down on illegal land hoarding, cover and other illegal activities and punish them.

\section{Optimizing tax and financial credit policy}

From Wuhan, the market situation, the current regulation policy still need from the national level to strengthen tax and financial credit regulation policy risks coordination and interaction, and differentiation of tax policy and financial regulation. Tax regulation, financial regulation is an important part of the real estate regulation and control, it is a kind of flexible control, should be according to the actual situation in the city ShiCe in ShiCe, should not be so in all regions, all the residents "one-size-fits-all."

First, gradient and orientation of tax policy: on the one hand, should according to different characteristics of different regional adjustment, because the "to" condition, because its ShiCe, tax authority down by the state and local governments to allow its purchasing power according to the jurisdiction of the housing price level, the social and economic comprehensive development level, etc., reasonable standards for real estate tax in the region, and then submitted to the state administration of taxation after examination and approval of the executive. For example, Wuhan, as a second-tier city, should adopt a relatively modest tax policy based on the fact of Wuhan, and balance the demand and supply structure of real estate.

Then it is to should be aimed at different levels, different number of the residents of the restrictions on the purchase, trading behavior, promote multi-level have direct tax policy, increase investment and speculative demand for housing costs, in order to reduce speculation, encouraging real rigid demand of residents to buy houses, to purchase from live sex with difficult people to discount. This will not only adjust the market's unreasonable behavior in time, but also increase the revenue of the country through taxation.

Secondly, strictly implement differentiated financial credit policies. One is adjusted by the means of using interest rate when the central government, the local government should be treated differently, such second-tier cities of Wuhan, the need to optimize the investment environment, according to the Wuhan economic development situation, taking the appropriate policy.

It is to live in sexual needs investment and speculative demand has differentiated credit policy, the rational allocation of financial resources supply through lending rates, such as encouraging just need people to buy, for priority to meet demand from live sex loans, for the first suite loan preferential interest rates; For more than two sets and housing, loan examination and approval strictly, improve the down-payment, raised its benchmark interest rate float level, more than three sets of restriction and housing loans, to limit and speculative real estate investment purchases.
It is adjusted to the housing structure, encouraging an area of ninety square meters, especially below seventy-five square meters of small and medium-sized family residential construction; offer certain preferential loan rates, limit highgrade luxury villas residential construction, execute the benchmark interest rate or a floating interest rate.

Thirdly, the tax and financial credit means are used as the two attacking players in the "combination" and need to cooperate with each other to meet and encourage the demand for home purchase and effectively curb the demand for speculative buying. First, we should set up a linkage mechanism to strengthen the linkage mechanism between the fiscal, taxation, housing and banking sectors on real estate management, and strengthen coordination among departments. Secondly, it is aimed at the treatment of real estate sectors, focusing on the use of credit policy in the trading session, playing the role of tax policy in the retaining links, and reasonably setting up the standard of property tax collection.

\section{REFERENCES}

[1] zhang xiaoyan. Research on administrative restriction - taking the real estate purchase order as an example [D]. Central national university, 2012.

[2] xu lingling. Research on the effect of China's housing restriction policy [D]. University of international business and economics, 2013.

[3] sun ying, luo xinbo, jiao aiying. The impact of the "restriction order" on the real estate market and housing consumption behavior - taking tianjin as an example [J]. China market, 2011 (48): 6-8.

[4] jia shenghua, mengzhen chao. The effect of real estate purchase restriction policy and its sustainability-empirical research based on the fluctuation relationship of the market value of Beijing commodity housing market [J]. China's economic problems, 2012 (5): 81-87. 